\title{
Optimization of the extraction of phenolic compounds from olive pomace using response surface methodology ${ }^{1}$
}

\author{
Bruna Wendt Böhmer-Maas 2* (D), Deborah Murowaniecki Otero ${ }^{3}$, Rui Carlos Zambiazi², Bianca Camargo Aranha ${ }^{2}$
}

10.1590/0034-737X202067030003

\begin{abstract}
Extraction of olive oil gives rise to large quantities of pomace and liquid effluents, since on average only $21 \%$ of the weight of the olive corresponds to oil, the remaining $79 \%$ consists of water, bark, pulp and stone. With the intention to make available new forms of use of this residue, this research was proposed, with aimed to optimize the extraction of phenolic compounds from olive pomace resulting from oil extraction using methanolic extracts. The analysis of phenolic compounds (TPC) and the evaluation of the antioxidant activity (AA) were performed by spectrophotometry, and the individual phenols were carried out by LC-ESI-qTOF-MS. The data were evaluated by the application of the response surface methodology (RSM). The condition that promoted the highest TPC in an extract was using $40 \%$ methanol, 70 ${ }^{\circ} \mathrm{C}$ and 180 minutes (extract 7). The highest AA was in the extract obtained with $40 \%$ methanol, $45^{\circ} \mathrm{C}$ and 180 minutes (extract 5). The highest individual phenol sum (IPS) was in the extract with $80 \%$ methanol, $45^{\circ} \mathrm{C}$ and 180 minutes (extract 6). Therefore, it is possible to conclude that the RSM was an interesting tool to measure the best conditions for extraction of phenolic compounds from olive pomace.
\end{abstract}

Keywords: residue; antioxidant activity; bioactive compounds.

\section{INTRODUCTION}

In European countries, where 95\% of the world's olive oil production is concentrated (International Olive Council, 2018), the inherent residues of olive oil production are considered an environmental problem.

The amount and characteristics of the waste generated will depend on the extraction form of the olive oil. There are currently two distinct olive oil extraction methods: the traditional method, using hydraulic press, and the continuous extraction by centrifugation method, which the olive industry has adopted in recent decades (Bhatnagar et al., 2014).

In the hydraulic press extraction, a solid pomace and olive mill waste waters are generated. In the centrifugal extraction method, two distinct systems may be used: the three-phase system and the two-phase system. In the two- phase centrifugation system, only one pomace containing up to $80 \%$ moisture, including peel, pulp and stone, without the formation of olive mill waste waters is generated.

In the three-phase centrifugation system a solid pomace is formed, consisting of the pulp, rind and stone of the fruit, containing 25 to $50 \%$ moisture and 5 to $7 \%$ of olive oil. In addition, olive mill waste waters are formed in larger volume than in the traditional method, due to the addition of water in the three-phase centrifugation process. Generally speaking, the olive mill waste water produced in this system are mostly made up of water (83 to $94 \%$ ), organic matter (4 to $16 \%$ ) and mineral salts ( 0.4 to $2.5 \%$ ) (Alú'datt et al., 2010).

The applications of olive pomace include their use as organic fertilizers and animal feed supplements (Innangi et al., 2017), fortification of food products, such as french

\footnotetext{
Submitted on August 27th, 2019 and accepted on March 26 th 2020.

${ }^{1}$ This work is part of the first author's Master Dissertation.

${ }^{2}$ Universidade Federal Pelotas, Programa de Pós-Graduação em Ciência e Tecnologia de Alimentos, Pelotas, Rio Grande do Sul, Brazil. zambiazi@gmail.com, bianca_camargo@live.com ${ }^{3}$ Universidade Federal da Bahia, Departamento de Ciência de Alimentos, Salvador, Bahia, Brazil. deborah.m.otero@gmail.com

*Corresponding author: bruna_bohmer@yahoo.com.br
} 
fries (Bouaziz et al., 2010), pasta and bread (Simonato et al., 2019), refined edible oils (Sánchez de Medina et al., 2012), and fermented milk (Aliakbarian et al., 2015).

The olive pomace resulting from the oil extraction accounts with about $99.95 \%$ of the total phenolic content (TPC) of the olive fruit, with only less than $0.05 \%$ migrating to olive oil (Cecchi et al., 2018).

The disposal of these residues may cause harmful effects on the environment due to its high organic content and phytotoxicity, due to recurrent high concentration of phenolic compounds, which ones have hard biological degradation, and antimicrobial effect, by affecting the processes of anaerobic digestion (Bhatnagar et al., 2014).

These residues can be substantially valued from the extraction of phenolic compounds that, given their wide range of bio-applications, can contribute to the recovery of this residue, with significant reduction of environmental impact. Therefore, the objective of this study was to optimize the extraction of phenolic compounds from olive pomace obtained in the two-phase extraction process using methanolic extracts.

\section{MATERIAL AND METHODS}

\section{Sample and Chemicals}

The olive pomace of two phase were supplied by a plant processing of olive oil, located at the city of Pinheiro Machado (31²9'59.2”S. 53³0'37.9”W) in Rio Grande do Sul, Brazil.

The samples were collected and subsequently frozen in an ultrafreezer at $-80^{\circ} \mathrm{C}$. Afterwards, the samples were lyophilized, promoting the removal of $99 \%$ of water. All chemical products were of the highest analytic degree. Hydroxybenzoic Acid, Gallic Acid, Rutin, Catechin, Ferulic Acid, Caffeic Acid, Chlorogenic Acid, Vanillic Acid, Coumaric Acid, Syringic Acid, Tyrosol, Oleuropein, Hydroxytyrosol, were supplied by Sigma-Aldrich (St. Louis, USA); methanol and Folin Ciocalteu $2 \mathrm{~N}$ solution were obtained from Merck (Darmstadt, Germany). Water was purified by an Ultra Purification System (Mega Purity).

\section{Experimental Design}

The extraction parameters were optimized using Response Surface Methodology (RSM). A Central Composition Design (CCD) was used to identify the relationship between response functions and independent variables, as well as determine conditions that optimize the extraction process for total phenol content (TPC), antioxidant activity (AA) and individual phenol summatory (IPS) of olive pomace extracts. Concentration of methanol (X1), temperature (X2) and time (X3) were chosen for independent variables. The range and center point values of three independent variables presented in Table 1 and the choice of methanol as solvent were based on the results of preliminary experiments. Each variable to be optimized was encoded in three levels $(-1,0$, +1 ). Eleven randomized experiments including three replicates as the central points were assigned based on CCD. The TPC, AA and IPS were selected as the responses (dependent variables) for the combination of the independent variables (Table 1). Three experiments of each condition were performed, and mean values were declared as measured responses. The predicted values of TPC, AA and IPS were obtained according to the recommended optimum conditions. The predicted and experimental values were compared in order to determine the validity of the model.

\section{Preparation of the extract}

Extraction by maceration was carried out in a water bath; where the lyophilized olive pomace sample ( $0.5 \mathrm{~g})$ was mixed with $15 \mathrm{~mL}$ of aqueous methanol at defined concentrations (Table 1) and kept under agitation according to the time (Table 1) and temperature (Table 1) as determined in CCD. After extraction, the extracts were centrifuged at 7,000 $\times \mathrm{g}$ for $15 \mathrm{~min}$, and the supernatants were filtered through filter paper and transferred to a 20 $\mathrm{mL}$ volumetric flask, for the final volume to be adjusted with the respective concentrations of aqueous methanol.

\section{Determination of total phenol content of olive pomace}

The TPC was measured by a photometric FolinCiocalteu assay according to Swain \& Hillis (1959) with a few adaptations. To $250 \mu \mathrm{L}$ extract were added $4000 \mu \mathrm{L}$ water and $250 \mu \mathrm{L}$ Folin-Ciocalteu reagent $\left(0.25\right.$ mol. $\left.\mathrm{L}^{-1}\right)$ in a centrifuge tube and allowed to react for 3 minutes. Subsequently, $500 \mu \mathrm{L}$ of sodium carbonate $\left(1.0 \mathrm{~mol} . \mathrm{L}^{-1}\right)$ was added. After 2 hours of reaction, the absorbance was measured in a spectrophotometer (Jenway 6705 UV/VIS) at $725 \mathrm{~nm}$. Standard curve was defined by known concentrations of gallic acid, ranging between 0 and 200 mg. $L^{-1}\left(R^{2}=0.9923\right)$, and results were expressed in milligrams of gallic acid equivalents (mg. $\left.\mathrm{kg}^{-1} \mathrm{GAE}\right)$.

\section{Determination of the antioxidant activity}

The antioxidant activity of the samples was assessed by standard antioxidant Trolox. Calibration curves of Trolox (concentrations 0-300 mg. $\mathrm{L}^{-1}$ ) were made in FRAP $\left(\mathrm{R}^{2}=0.9954\right)$ post-column assays, and the results were expressed as Trolox equivalent antioxidant capacity (mg.kg-1 TEA). The analysis was conducted according to the method described by Silva (2013), with few modifications. To the extract was added $3000 \mu \mathrm{L}$ of the FRAP reagent, and the reaction was conducted under heating at $37^{\circ} \mathrm{C}$ for 30 minutes. The reduction of the $\mathrm{Fe}^{3+}$ 
to $\mathrm{Fe}^{2+}$ complex was obtained by reading the absorbance at $595 \mathrm{~nm}$ in a spectrophotometer (Jenway 6705 UV/VIS).

\section{Identification of the Phenolic Compounds by LC-ESI-qTOF-MS}

The same extracts analyzed for total phenolic content and antioxidant activity by spectrophotometer was used for identification of the phenolic compounds by LC-ESIqTOF-MS. Samples were filtered through a $0.22 \mathrm{mM}$ nylon membrane filter (Merck Millipore Corporation, Germany). After the samples were prepared, $10 \mu \mathrm{L}$ was injected in a liquid chromatograph (UFLC, Shimadzu, Japan) coupled to a high-resolution mass spectrometer of the quadrupole type-flight time (Maxis Impact, Bruker Daltonics, Germany). A pre-column C18 $(2.0 \times 4 \mathrm{~mm})$ and Luna C18 column $(2.0 \times 150 \mathrm{~mm}, 100 \AA, 3 \mu \mathrm{m})$ (Phenomenex Torrance, USA) were used for the chromatographic separation using the mobile phases: water acidified with $0.1 \%$ formic acid (eluent $\mathrm{A}$ ) and acetonitrile acidified with $0.1 \%$ formic acid (eluent B). For separation, a gradient was used: 0-2 min, $10 \% \mathrm{~B} ; 2-15 \mathrm{~min}, 10-75 \% \mathrm{~B} ; 15-18 \mathrm{~min}, 90 \% \mathrm{~B} ; 18-21 \mathrm{~min}$ $90 \% \mathrm{~B} ; 21-23 \mathrm{~min}, 10 \% \mathrm{~B}, 23-30 \mathrm{~min}, 10 \% \mathrm{~B}, 0.2 \mathrm{~mL} \cdot \mathrm{min}^{-1}$ flow and the column temperature was set at $40{ }^{\circ} \mathrm{C}$. The mass spectrometer was operated in the ESI negative modes with spectra acquired over a mass range of m/z 50 to 1200 , with capillary voltage at $3.5 \mathrm{kV}$, nebulization gas pressure $\left(\mathrm{N}_{2}\right)$ of 2 bar, drying gas at $8 \mathrm{~L} \mathrm{min"1,} \mathrm{source} \mathrm{temperature}$ $180{ }^{\circ} \mathrm{C}$, RF collision of $150 \mathrm{Vpp}$; transfer $70 \mathrm{mS}$ and prepulse storage of $5 \mathrm{mS}$. The equipment was calibrated with $10 \mathrm{mmol} . \mathrm{L}^{-1}$ sodium formate, covering the acquisition range of $\mathrm{m} / \mathrm{z} 50$ to 1200. Automatic MS/MS experiments were performed by adjusting the collision energy values as follows: m/z 100, $15 \mathrm{eV}$; m/z 500, $35 \mathrm{eV}$; m/z 1000, $50 \mathrm{e} \mathrm{V}$, using nitrogen as the collision gas (Hoffmann et al., 2016). Data from MS and MS/MS were processed using Data analysis software 4.0 (Bruker Daltonics, Germany). Phenolic compounds were characterized by the UV/Vis spectrum (210-800 nm), and the exact mass and MSn fragmentation patterns were compared to the equipment library data and databases (Metlin, MassBank, Kegg Compound, ChemSpider) and compared with the isotopic standard. The quantification of phenolic compounds were performed by external calibration curve with eight concentrations $(0.039 ; 0.078 ; 0.156 ; 0.312 ; 0.625 ; 1.250$; 2.50 and $\left.5 \mu \mathrm{g} . \mathrm{mL}^{-1}\right)$ with standards of each compound
(Hydroxybenzoic acid $\left(\mathrm{R}^{2}=0.9988\right)$, Coumaric acid $\left(\mathrm{R}^{2}=\right.$ 0.9997), Vanillic acid $\left(R^{2}=0.9999\right)$, Galic acid $\left(R^{2}=0.9999\right)$, Caffeic acid $\left(R^{2}=1.0000\right)$, Ferulic acid $\left(R^{2}=0.9999\right)$, Syringic acid $\left(R^{2}=0.9996\right)$, Chlorogenic acid $\left(R^{2}=0.99969\right)$, Rutin $\left(\mathrm{R}^{2}=0.9998\right)$, Catechin $\left(\mathrm{R}^{2}=0.9989\right)$, Oleuropein $\left(\mathrm{R}^{2}=\right.$ 0.9996), Hydroxytyrosol $\left(R^{2}=0.9962\right)$, Tyrosol $\left(R^{2}\right.$ $=0.9924)$ ), and the results were expressed in mg. $\mathrm{kg}^{-1}$.

\section{Statistical Analysis}

To evaluate the results for TPC, AA and IPS for experimental designs, it was used analysis of variance (ANOVA), which was carried out using the software Statistica 6.0 at level of $95 \%$ of confidence $(p<0.05)$. The experiments and analytical measurements were carried out in triplicate. The adequacy of the model was determined by evaluating the lack of fit, the coefficient of determination $\left(\mathrm{R}^{2}\right)$, and the $\mathrm{F}$ test value obtained from the ANOVA. The Tukey test was used for comparison of the means at $5 \%$ of significance. The relationship between the independent variables and the response variables was demonstrated by the $3 \mathrm{D}$ response surface plots.

\section{RESULTS AND DISCUSSIONS}

\section{Optimization of phenolic compounds extraction}

As shown in Table 2, concentrations of TPC ranged from 20886.2 to $23061.2 \mathrm{mg} . \mathrm{kg}^{-1}$ GAEof dried olive pomace, and all samples differed significantly by Tukey test ( $\mathrm{p}<$ $0.05)$

The highest concentration of phenolic compounds was obtained by the extract 7 (23061.2 mg.kg-1 GAE), in which the methanol concentration was $40 \%$ (level -1), the temperature of $70{ }^{\circ} \mathrm{C}($ level +1$)$ and time of 180 minutes (level +1 ); followed by the extract 8 , in which the concentration of $22809.4 \mathrm{mg} \cdot \mathrm{kg}^{-1} \mathrm{GAE}$ was obtained. The lowest yield was obtained by the extract 3 (20886.2 mg.kg$\left.{ }^{1} \mathrm{GAE}\right)$, in which the methanol concentration was $40 \%$ ($1)$, the temperature of $70^{\circ} \mathrm{C}(+1)$ and the time of 60 minutes $(-1)$. Similar results were reported in a study that evaluated the efficacy of ultrasound in the extraction of TPC from olive pomace, with $22020 \mathrm{mg} \cdot \mathrm{kg}^{-1} \mathrm{GAE}$ (Goldsmith et al., 2018). The effects of the variables on the overall yield of the extraction were determined (Figure 1). For this, linear models with a $95 \%$ confidence interval were considered.

Table 1: Independent variable and coded levels used in Central Composition Design

\begin{tabular}{lcccc}
\hline \multirow{2}{*}{ Independent variable } & \multirow{2}{*}{ Units } & \multicolumn{3}{c}{ Coded Levels } \\
\cline { 3 - 5 } & & $\mathbf{- 1}$ & $\mathbf{0}$ & $\mathbf{+ 1}$ \\
\hline Methanol concentration (X1) & $\%$ & 40 & 60 & 80 \\
Temperature (X2) & ${ }^{\circ} \mathrm{C}$ & 45 & 57.5 & 70 \\
Time (X3) & minutes & 60 & 120 & 180 \\
\hline
\end{tabular}




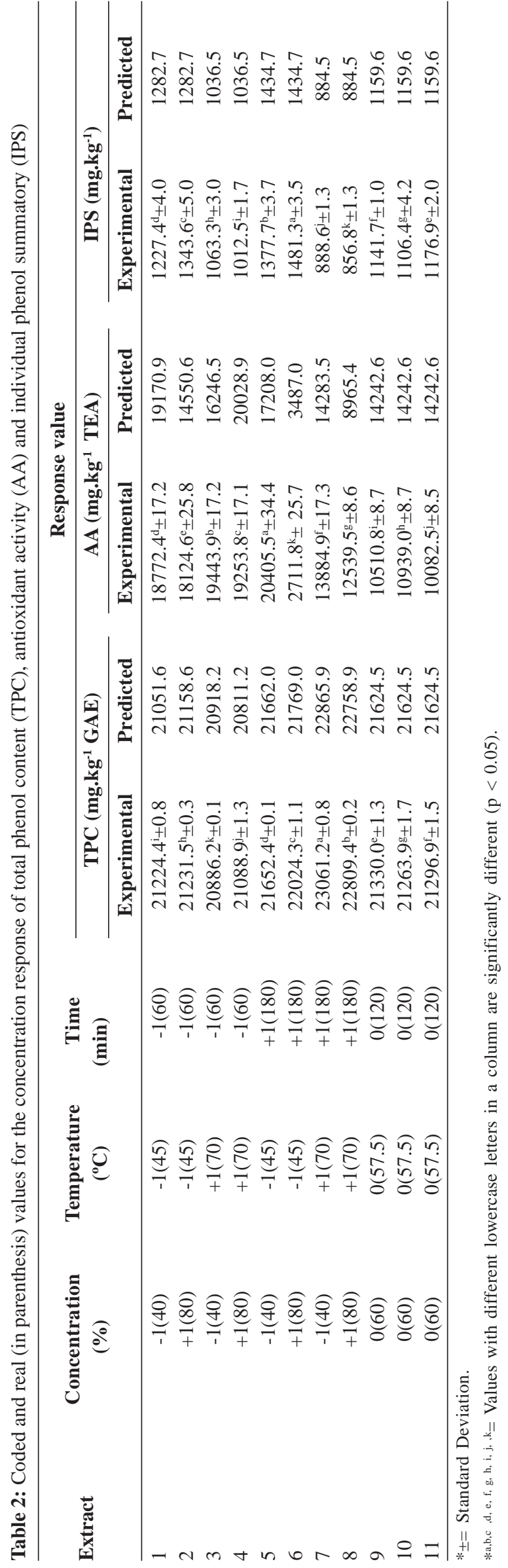

The effects considered significant can be observed from the $p$ value, where all values smaller than 0.05 are significant. The $\mathrm{p}$ value is the probability of observing a statistical test value greater than or equal to that found. This value is used to evaluate the significance of the coefficients, so that the smaller the $\mathrm{p}$ value, the greater the significance of the coefficient of variation.

The time variable presented positive and significant effect, when the extraction time was increased from level 1 (60 min) to level +1 (180 min), there was an increase in the effect of 1279.1. This can be justified by the increase in the contact time between the solvent and the sample, which leads to a greater penetration of the solvent and, consequently, favors the extraction of the phenolic compounds. According to Yingngam et al. (2015), reduced extraction times do not allow efficient penetration of the solvent into the extract, preventing the extraction of the compounds of interest. Some studies corroborate these findings, since an increase in TPC content was observed due to an increase in extraction time (Sun et al., 2011; Dent et al., 2013; Chen et al., 2018).

The interaction between temperature and extraction time promoted a positive and significant effect on the extraction of phenolic compounds. With the increase of the extraction time and the heating of the sample, the integrity of the cell wall weakened, promoting greater extraction of these compounds, due to the increased solubility with the solvent (Liu et al., 2013). The temperature had a positive and significant effect, when this variable was elevated to $-1\left(45^{\circ} \mathrm{C}\right)$, at $+1\left(70^{\circ} \mathrm{C}\right)$ there was an increase in the effect of 428.28 (Figure 1). This is justified because the high temperature favors the mass transfer process, leading to the reduction of the viscosity of the solvent and facilitating its penetration, besides favoring the degradation of the matrix and the cellular structure, which makes the cells more permeable (Tabaraki et al., 2012; Liu et al., 2013). In addition, there is a weakening of the interactions between phenolic compounds and proteins, and between phenolic compounds and polysaccharides; therefore, increasing the rate of diffusion. Yuan et al. (2018) observed similar results in the optimization of phenolic compounds extraction by maceration from Oregon hazelnut residues in the United States.

The interaction between the methanol concentration and the temperature showed a significant negative effect. This behavior can be related to the reduction of the dielectric constant of the aqueous solution mixture with increasing temperature, which reduces the polarity of the solvent, resulting in a lower extraction of phenolic compounds (Chiang et al., 2017). The solvent concentration variable as well as its interaction with time were not significant. Equation 1 presents the first order 
coded model, which describes the TPC as a function of the independent variables (concentration, temperature and time).

The model was validated by analysis of variance (Table 3), in which a correlation coefficient of 0.94 was obtained, indicating that the model was significant.

$\mathrm{TCP}=21624.46+214.14$ temperature +639.54 time -53.51 concentration tmperature +334.34 temperature time

The $\mathrm{F}_{\text {calculated }}$ values of 583.19 and $\mathrm{F}_{\text {tabulated }}$ of 4.46 (Table 1 in supplementary material), demonstrate that the model was predictive, thus allowing the construction of the response surfaces shown in Figures 2 (a), (b) and (c).(b)

In Figure 2 (a), it is possible to observe that with the increase of temperature and time variables to higher levels there is a higher concentration of TPC, which is evident by the intensification of the dark color presented in the graph. Figure 2 (b) shows that the region with the highest TPC is at the highest levels of extraction times, however, the methanol concentration had no influence on the TPC, and in Figure 2 (c) it is possible to observe that the darkest and highest TPC region is concentrated at the highest temperature and concentration levels.

\section{Determination of the AA by FRAP Assay}

According to Table 2 all samples differed significantly by Tukey test ( $\mathrm{p}<0.05$ ), and the highest AA by the FRAP method was obtained in extract 5 (20405.5 mg.kg-1 TEA), in which the methanol concentration was $40 \%(-1)$, the temperature of $45^{\circ} \mathrm{C}(-1)$ and time of 180 minutes $(+1)$. The lowest AA was observed in extract $6\left(2711.8 \mathrm{mg} \cdot \mathrm{kg}^{-1} \mathrm{TEA}\right)$, where the methanol concentration was $80 \%(+1)$, temperature of $45^{\circ} \mathrm{C}(-1)$ and time of 180 minutes $(+1)$.

Extracts 5 and 6 showed a large difference in AA, although only differing in methanol concentration, probably because the set of parameters used promoted lower extraction of compounds in extract 6 .

The effects of the variables on AA by the FRAP method (Figure 3) were determined, where linear models with a 95\% confidence interval were considered.According to Figure 3, the time was the variable that presented the most expressive effect. When time was elevated from level -1 $(60 \mathrm{~min})$ to +1 (180 $\mathrm{min})$, it was promoted a reduction effect of AA of 6513.3, probably because in longer extraction periods there was a greater degradation of compounds with antioxidant activity.

Solvent concentration showed a negative and significant effect on the AA response, when it was increased from level -1 (40\%) to level +1 (80\%), there was a reduction of AA in 4969.3. The interaction between solvent concentration and time presented a negative and significant effect. Similar result also was reported in previous study (Aybastier et al., 2013). The interaction between solvent concentration and temperature exerted a positive and significant effect against the AA response by the FRAP method. The temperature variable presented $\mathrm{p}>0.05$, and consequently did not present statistical significance. Similarly, the interaction between temperature and time had no significant effect on AA response by the FRAP method.

Equation 2 presents the coded model, which describes the AA by the FRAP method, as a function of the independent variables (concentration, temperature and time).

$\mathrm{AA}=14242.6-2484.6$ concentration +638.5 time -3256.6 time +2100.7 concentration temperature -2275.15 concentration +638.5 time

The model was validated by analysis of variance, in which a correlation coefficient of 0.84 was obtained,

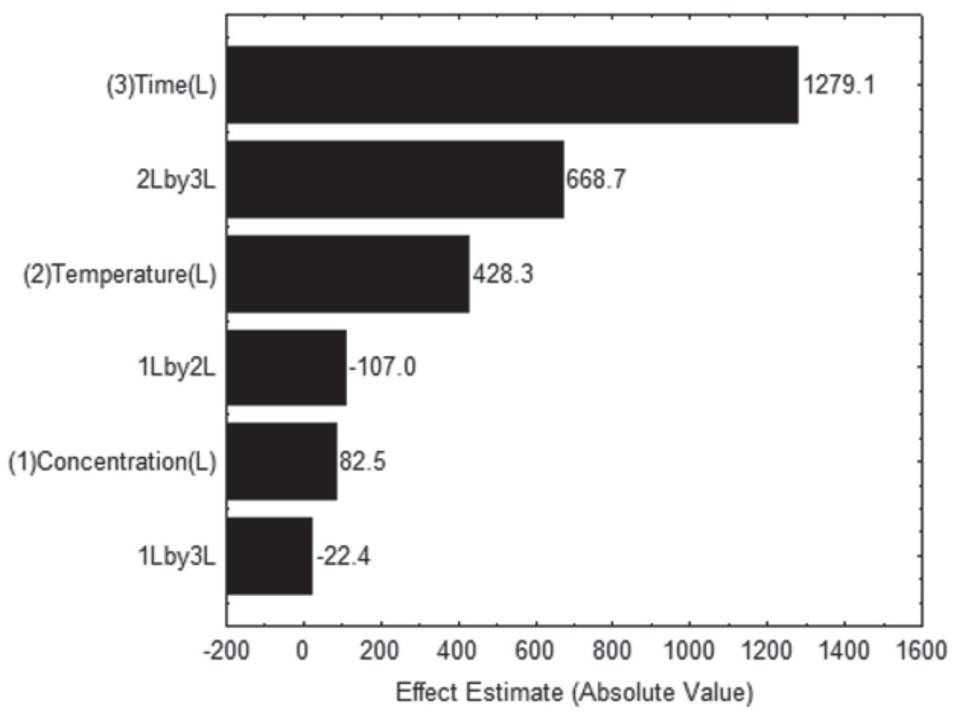

Figure 1: Estimated effects of concentration (1), temperature (2) and time (3) parameters on TPC response. 
indicating that the model was significant. The $\mathrm{F}_{\text {calculated }}$ values of 206.8 and $\mathrm{F}_{\text {tabulated }}$ of 4.46 demonstrated that the model was predictive, thus allowing the construction of the response surfaces, shown in Figures 4 (a), (b) and (c).

According to Figure 4 (a), the darker region of the graph (higher AA) is concentrated at lower levels of the time variable; however, temperature had no influence on AA. In Figure 4 (b) the darkest region is concentrated at the lowest levels of solvent concentration and time, and in Figure 4 (c) it can be seen that the darkest region is concentrated at the lowest level of concentration and temperature.

\section{Identification of the Phenolic Compounds by LC-ESI-qTOF-MS}

According to table 3 , the sum of the compounds ranged from 856.8 to $1481.3 \mathrm{mg} \cdot \mathrm{kg}^{-1}$. In ascending order of average concentration were found: catechin $\left(0.68 \mathrm{mg} . \mathrm{kg}^{-1}\right)$, ferulic
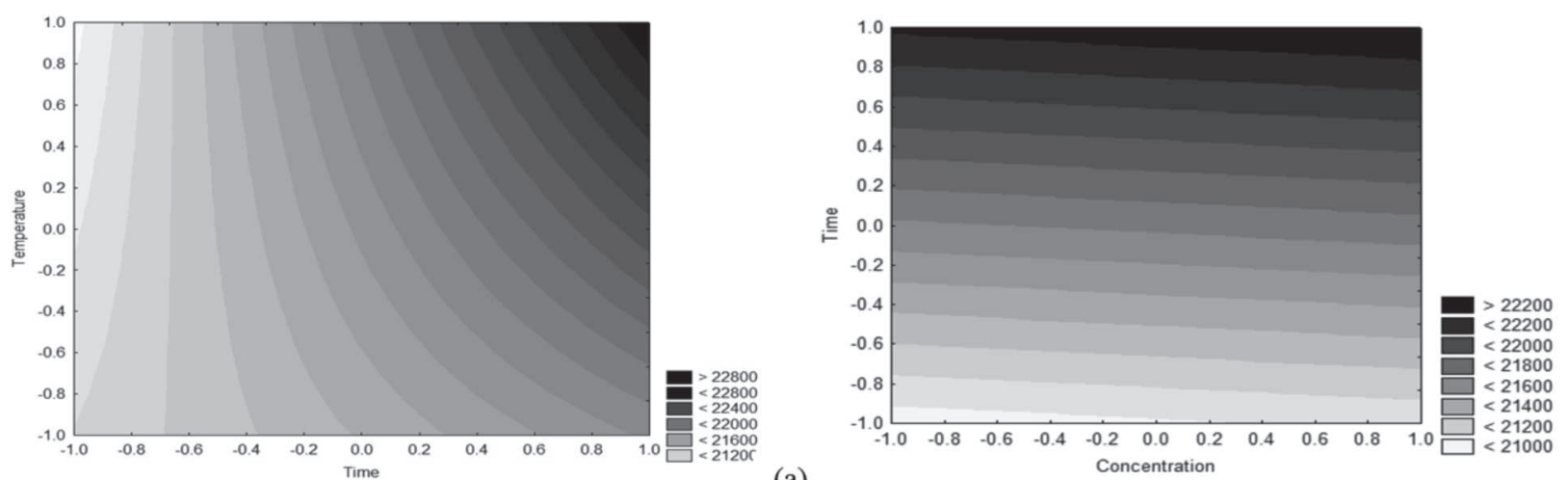

(a)

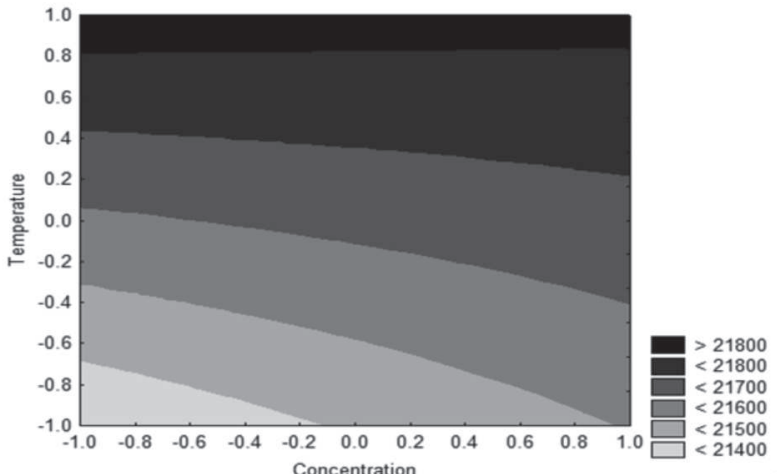

(c)

Figure 2: Surface response of total phenolic compounds concentration.

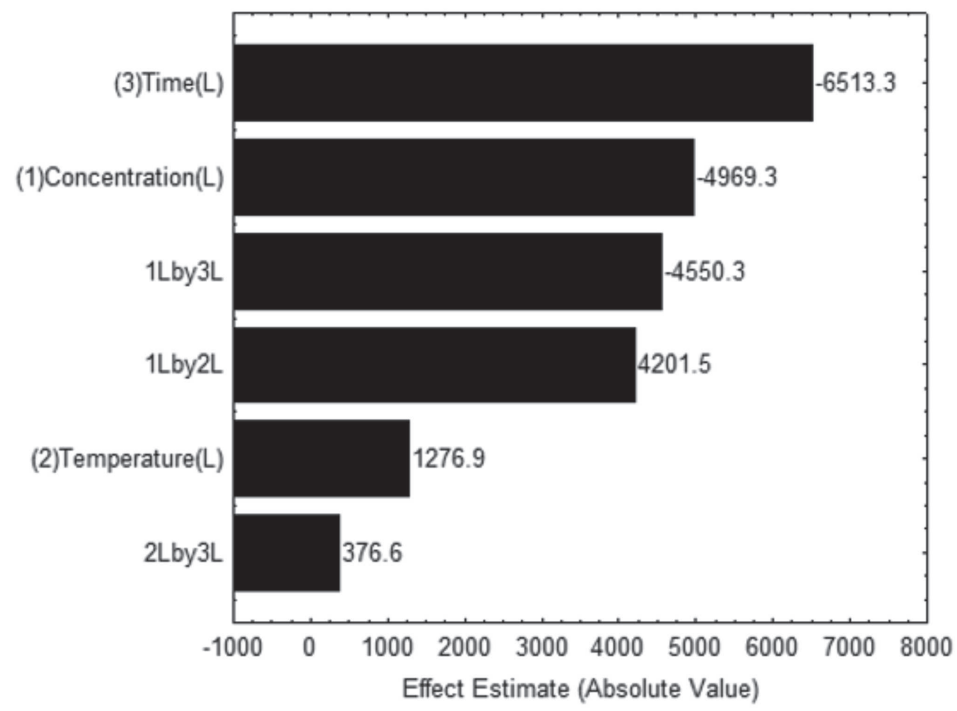

Figure 3: Estimated effects of concentration (1), temperature (2) and time (3) parameters on AA response. 
acid (1.75 mg. $\left.\mathrm{kg}^{-1}\right)$, hydroxybenzoic acid $\left(2.73 \mathrm{mg} . \mathrm{kg}^{-1}\right)$, gallic acid $\left(4.07 \mathrm{mg} . \mathrm{kg}^{-1}\right)$, rutin $\left(4.52 \mathrm{mg} \cdot \mathrm{kg}^{-1}\right)$ coumaric acid (4.55 mg.kg-1 $)$, oleuropein $\left(6.16 \mathrm{mg} \cdot \mathrm{kg}^{-1}\right)$, chlorogenic acid (6.24 mg. $\left.\mathrm{kg}^{-1}\right)$, vanillic acid (10.37 mg. $\left.\mathrm{kg}^{-1}\right)$, caffeic acid (18.38 mg. $\left.\mathrm{kg}^{-1}\right)$, syringic acid (132.5 mg. $\left.\mathrm{kg}^{-1}\right)$, hydroxytyrosol (136.7 mg. $\left.\mathrm{kg}^{-1}\right)$ and tyrosol $\left(833.7 \mathrm{mg} \cdot \mathrm{kg}^{-1}\right)$.

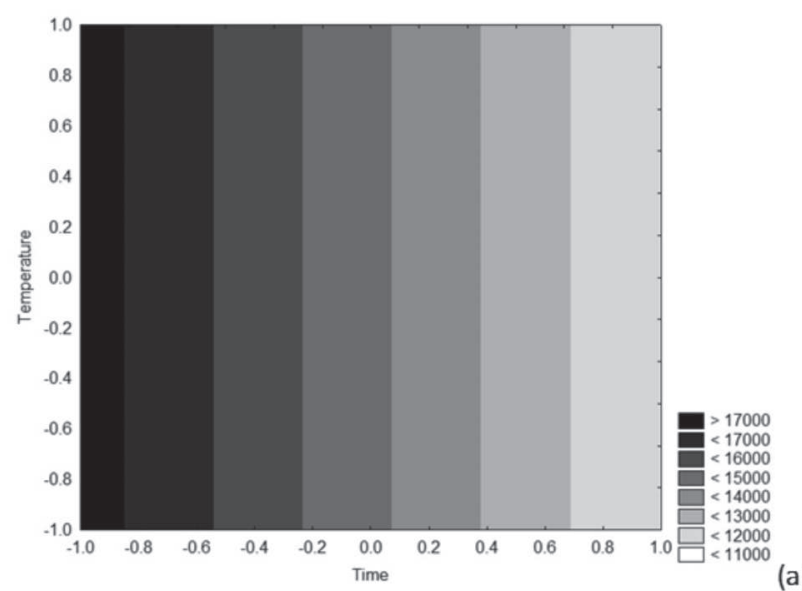

In general, phenolic alcohols were present in higher concentration (930.4 mg. $\mathrm{kg}^{-1}$ ), followed by phenolic acids (173.8 mg. $\left.\mathrm{kg}^{-1}\right)$, secoiridoids (6.16 mg. $\mathrm{kg}^{-1}$ ) and flavonoids (5.11 mg.kg-1).

Albahari et al. (2018) optimized extraction of olive pomace phenolic compounds by applying ultrasound, and

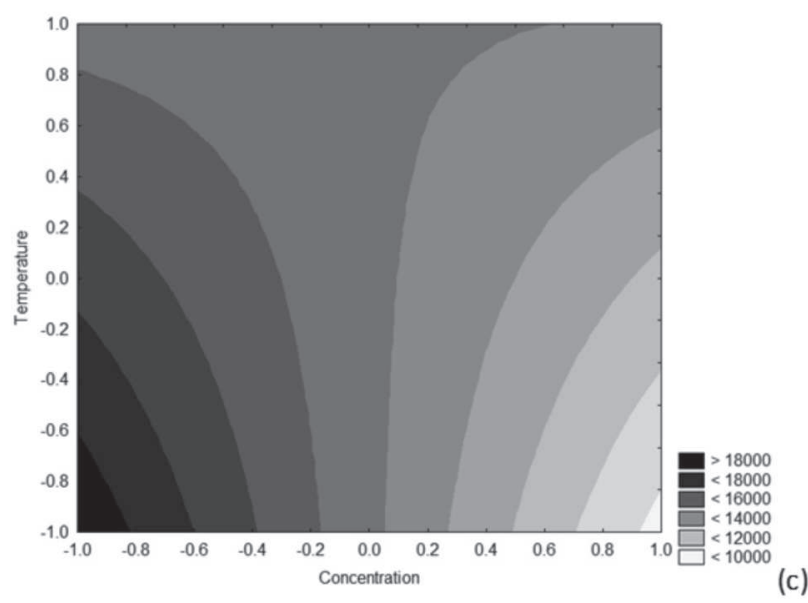

Figure 4: Surface response of antioxidant activity in extracts.

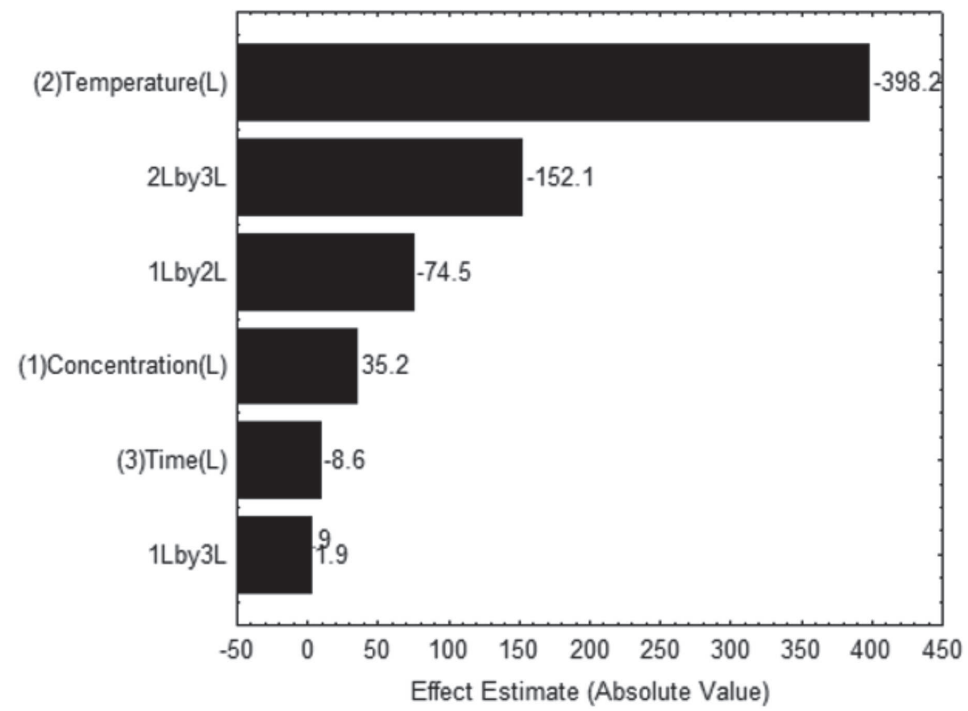

Figure 5: Estimated effects of concentration (1), temperature (2) and time (3) parameters on IPS response. 


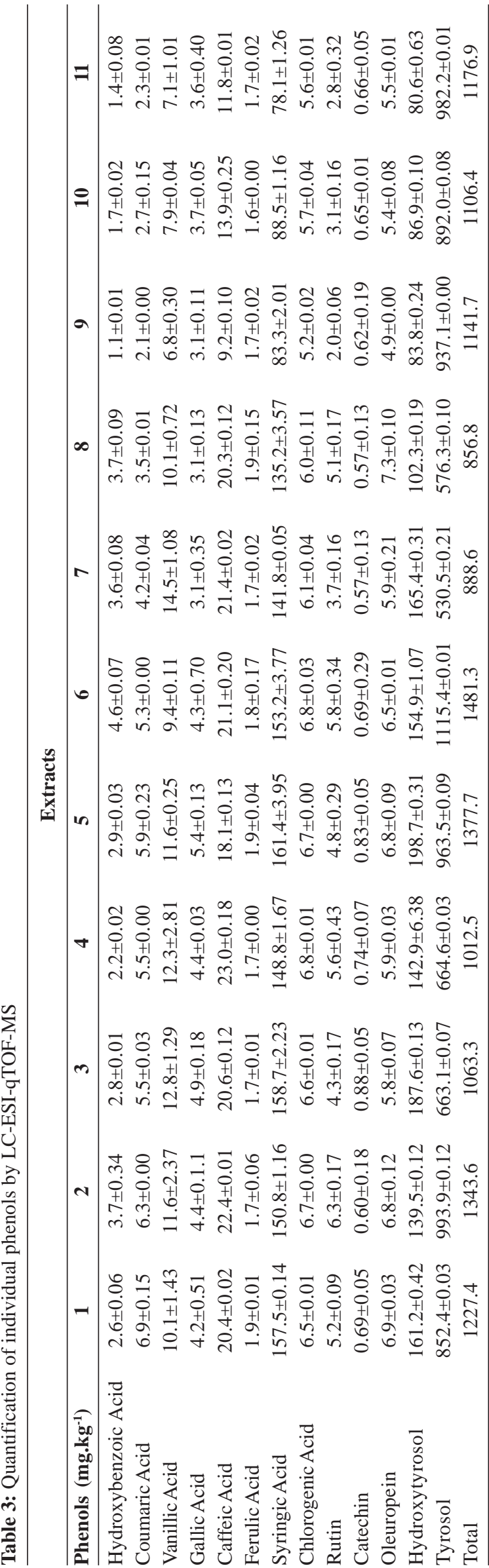

they observed the concentration of $1117 \mathrm{mg} \cdot \mathrm{kg}^{-1}$ of tyrosol, similar to that found in the present study for trial 6 (1115.4 mg.kg-1), which was obtained by $80 \%$ methanol, $45^{\circ} \mathrm{C}$ and 180 minutes.

The extract 5 presented the highest concentration of hydroxytyrosol (198.7 mg. $\mathrm{kg}^{-1}$ ), wich was obtained with $40 \%$ methanol, $45^{\circ} \mathrm{C}$ and 180 minutes. Similar result was reported by Chanioti \& Tzia (2018), whose optimized the extraction of phenolic compounds from olive pomace by assisted ultrasound (230 mg. $\mathrm{kg}^{-1}$ ).

The concentration of hydroxytyrosol and tyrosol observed in the present study for olive pomace was higher than the content reported for Blanquette olive oil (11 and $1 \mathrm{mg} \cdot \mathrm{kg}^{-1}$, respectively) and Rougette (5 and $11 \mathrm{mg} \cdot \mathrm{kg}^{-1}$, respectively) found by Yakhlef et al. (2018).

In the literature, the main compounds described in olive pomace are oleuropein, hydroxytyrosol, tyrosol, luteolin, apigenin, vanillic acid, caffeic acid and rutin (Servili et al., 1999; Alu' datt et al., 2010; Sánchez de Medina et al., 2012; Chanioti \& Tzia, 2018; Albahari et al., 2018; Seçmeler et al., 2018; Nunes et al., 2018). In the present study, different molecules than those previously described were found (galangin, kaempferol and chrisin), which may be related to the optimization of the extraction conditions, which results in a more efficient removal of the phenolic compounds from olive pomace.

Differences in the extraction variables did not qualitatively modify the phenol profile, but it was observed quantitatively differences, since all the compounds were identified in the 11 extracts; however, at different concentrations (Table 3).

As shown in Table 2, the highest IPS was obtained in the trial 6 (1481.3 mg. $\mathrm{kg}^{-1}$ ) (Table 2), which was obtained by $80 \%$ methanol, $45^{\circ} \mathrm{C}$ and 180 minutes, and all samples differed significantly by Tukey test ( $\mathrm{p}<0.05$ ).

It was possible to observe by the analysis of effects of the variables (Figure 5) that when the temperature variable was elevated from level -1 to +1 there was a reduction in the effect of 398.2 against the analyzed response. Similarly, the interaction between temperature and time promoted a significant and negative effect, which indicates that when these variables were elevated from -1 to +1 there was a reduction in the effect of 152.1.

In contrast, the variables concentration, interaction between concentration and temperature, interaction between concentration and time, in addition to the variable time analyzed alone, did not exert a significant effect on the IPS response, since they presented $p>0.05$ (Figure 5).

Equation 3 presents the coded model, which describes the IPS as a function of the independent variables (concentration, temperature and time).

IPS $=1159.6-199.1$ temperature -76.0 temperature time 

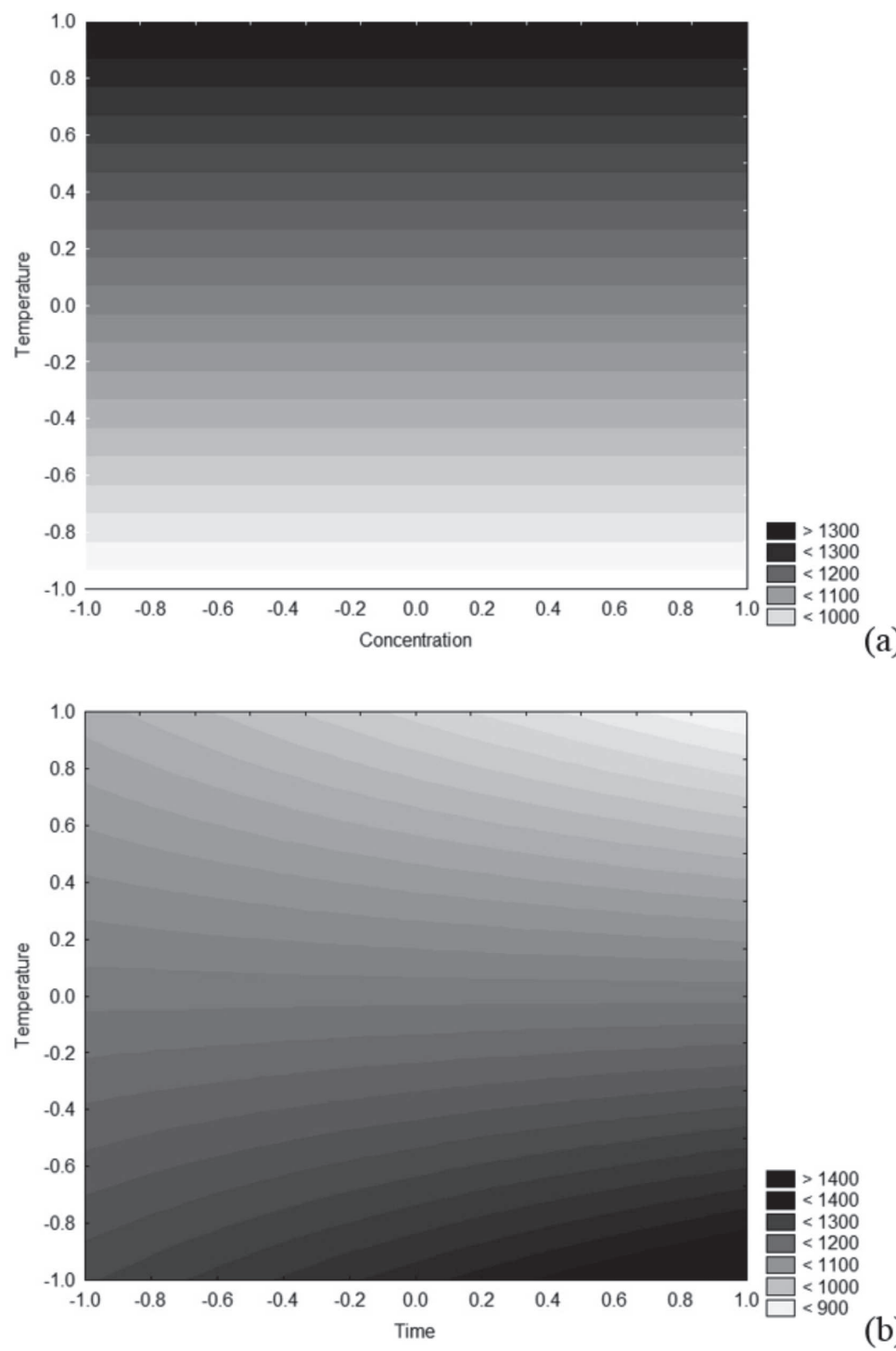

Figure 6: Surface response of individual phenol summatory.

The model was validated by analysis of variance (Table 3), in which a correlation coefficient of 0.98 was obtained, indicating that the model was significant. The $\mathrm{F}_{\text {calculated }}$ values of 28.43 and $\mathrm{F}_{\text {tabulated }}$ of 4.46 (Table 1 in supplementary material), demonstrate that the model was predictive, thus allowing the construction of the response surfaces shown in Figures 6 (a) and (b).

In Figure 6 (a), it is observed that the darkest region (highest IPS) is concentrated at the highest temperature level, regardless of the concentration level. Figure 6 (b) shows that the region with the highest IPS is located at the highest extraction time level and lowest temperature level.

\section{ACKNOWLEDGEMENTS, FINANCIAL SUPPORT AND FULL DISCLOSURE}

The authors would like to acknowledge Conselho Nacional de Desenvolvimento Cientifico e Tecnológico (CNPq), and Coordenação de Aperfeiçoamento de Pes- soal de Nível Superior (CAPES) for founding the research. The authors declare that there is no conflict of interest in carrying out the research and publishing the manuscript.

\section{CONCLUSIONS}

Through surface response methodology it was possible to observe that the conditions that promoted the highest TPC were obtained by using $40 \%$ methanol, $70{ }^{\circ} \mathrm{C}$ and 180 minutes. The highest AA was found in the extract obtained with $40 \%$ methanol, $45^{\circ} \mathrm{C}$ and 180 minutes. The extract that showed the highest IPS was the one obtained using $80 \%$ methanol, $45^{\circ} \mathrm{C}$ and 180 minutes.

The response surface methodology proved to be a great alternative for reducing the number of tests, allowing the optimization of the phenol extraction process with reduced number of experiments, promoting reduction on cost and analysis time. 


\section{REFERENCES}

Alu'datt MH (2010) Optimization, characterization and quantification of phenolic compounds in olive cake. Food Chemistry, 123:117-122.

Albahari P, Jug M, Radiæ K, Jurmanoviæ S, Brnèiæ M, Brnèiæ SR \& Ėepo DV (2018) Characterization of olive pomace extract obtained by cyclodextrin-enhanced pulsed ultrasound assisted extraction. LWT-Food Science and Technology, 92:22-31.

Aliakbarian B, Casale M, Paini M, Casazza AA, Lanteri S \& Perego $P$ (2015) Production of a novel fermented milk fortified with natural antioxidants and its analysis by NIR spectroscopy. LWTFood Science and Technology, 62:376-383.

Aybastýer Ö, Ipýk E, Pahin S \& Demir C (2013) Optimization of ultrasonic-assisted extraction of antioxidant compounds from blackberry leaves using response surface methodology. Industrial crops and products, 44:558-565.

Bhatnagar A, Kaczala F, Hogland W, Marques M, Paraskeva C, Papadakis V \& Sillanpää M (2014) Valorization of solid waste products from olive oil industry as potential adsorbents for water pollution control - A review. Environmental Science and Pollution Research, 2:268-298.

Bouaziz M, Feki I, Ayadi M, Jemai H \& Sayadi S (2010) Stability of refined olive oil and olive pomace oil added by phenolic compounds from olive leaves. European Journal of Lipid Science and Technology, 112:894-905.

Cecchi L, Migliorini M, Zanoni B, Breschi C \& Mulinacci N (2018) An effective HPLC based approach for the evaluation of the content of total phenolic compounds transferred from olives to virgin olive oil during the olive milling process. Journal of the Science of Food and Agriculture, 98:3636-3643.

Chanioti S \& Tzia C (2018) Extraction of phenolic compounds from olive pomace by using natural deep eutectic solvents and innovative extraction techniques. Innovative Food Science \& Emerging Technologies, 48:228-239.

Chen S, Zeng Z, Hu N, Bai B, Wang H \& Suo Y (2018) Simultaneous optimization of the ultrasound-assisted extraction for phenolic compounds content and antioxidant activity of Lycium ruthenicum Murr. fruit using response surface methodology. Food Chemistry, 242:01-08.

Chiang PS, Lee DJ, Whiteley CG \& Huang CY (2017) Antioxidant phenolic compounds from Pinus morrisconicola using compressional-puffing pretreatment and water-ethanol extraction: Optimization of extraction parameters. Journal of the Taiwan Institute of Chemical Engineers, 70:07-14.

Dent M, Dragovic-uzelac V, Penic M, Brncic M, Bosiljkov T \& Levaj B (2013) The effect of extraction solvents, temperature and time on the composition and mass fraction of polyphenols in Dalmatian wild sage (Salvia officinalis L.) extracts. Food Technology and Biotechnology, 51:84-91.

Goldsmith CD, Vuong QV, Stathopoulos CE, Roach PD \& Scarlett CJ (2018) Ultrasound increases the aqueous extraction of phenolic compounds with high antioxidant activity from olive pomace. LWT-Food Science and Technology, 89:284-290.

Hoffmann JF, Zandoná GP, Santos PS, Dallmann CM, Madruga FB, Rombaldi CV \& Chaves FC (2016) Stability of bioactive compounds in butiá (Butia odorata) fruit pulp and nectar. Food Chemistry, 237:638-644

Innangi M, Niro E, D'ascoli R, Danise T, Proietti P, Nasini L, Regni L, Castaldi S \& Fioretto A (2017) Effects of olive pomace amendment on soil enzyme activities. Applied Soil Ecology, 119:242-249.
International Olive Council (2018) Statistics. Available at: http:/ /www.internationaloliveoil.org/estaticos/view/131-world-oliveoil-figures. Accessed on: September 10 $10^{\text {th }}, 2019$.

Liu Z, Dang J, Wang Q, Yu M, Jiang L, Mei L \& Tao Y (2013) Optimization of polysaccharides from Lycium ruthenicum fruit using RSM and its anti-oxidant activity. International Journal of Biological Macromolecules, 61:127-134.

Nunes MA, Costa AS, Bessada S, Santos J, Puga H, Alves RC \& Oliveira MBP (2018) Olive pomace as a valuable source of bioactive compounds: A study regarding its lipid-and watersoluble components. Science of the total environment, 644:229236.

Sánchez de Medina V, Priego-Capote F, Luque de Castro MD (2012) Characterization of refined edible oils enriched with phenolic extracts from olive leaves and pomace. Journal of agricultural and food chemistry, 60:5866-5873.

Seçmeler Ö, Üstündað ÖG, Fernández-Bolaños J \& RodríguezGutiérrez G (2018) Effect of subcritical water and steam explosion pretreatments on the recovery of sterols, phenols and oil from olive pomace. Food chemistry, 265:298-307.

Servili M, Baldioli M, Selvaggini R, Macchioni A \& Montedoro G (1999) Phenolic compounds of olive fruit: one-and twodimensional nuclear magnetic resonance characterization of nüzhenide and its distribution in the constitutive parts of fruit. Journal of Agricultural and Food Chemistry, 47:12-18.

Simonato B, Trevisan S, Tolve R, Favati F \& Pasini G (2019) Pasta fortification with olive pomace: Effects on the technological characteristics and nutritional properties. LWTFood Science and Technology, 114:108368.

Sun Y, Wengin X, Wengin Z \& Qiuhui H (2011) Optimizing the extraction of phenolic antioxidants from kudingcha made from Ilex kudingcha C.J. Tseng by using response surface methodology. Separation and Purification Technology, 78:311-320.

Swain T \& Hillis WE (1959) The phenolic constituents of Prunus domestica L.- The quantitative analysis of phenolic constituents. Journal of the Science of Food and Agriculture, 10:63-68.

Tabaraki R, Heidarizadi E \& Benvidi A (2012) Optimization of ultrasonic-assisted extraction of pomegranate (Punica granatum L.) peel antioxidants by response surface methodology. Separation and Purification Technology, 98:1623

Yakhlef W, Arhab R, Romero C, Brenes M, Castro A \& Medina E (2018) Phenolic composition and antimicrobial activity of Algerian olive products and by-products. LWT- Food Science and Technology, 93:323-328.

Yingngam B, Supaka N \& Rungseevijitprapa W (2015) Optimization of process parameters for phenolics extraction of Cratoxylum formosum ssp. formosum leaves by response surface methodology. Journal of Food Science and Technology, $52: 129-140$

Yuan B, Lu M, Eskridge KM, Isom LD \& Hanna MA (2018) Extraction, identification, and quantification of antioxidant phenolics from hazelnut (Corylus avellana L.) shells. Food Chemistry, 244:07-15. 